\begin{tabular}{|c|c|}
\hline \multirow{3}{*}{ 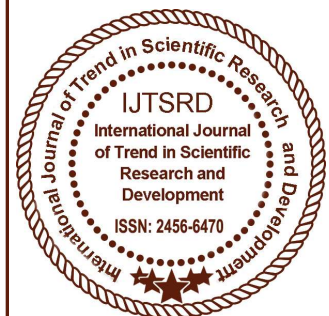 } & $\begin{array}{l}\text { International Journal of Trend in Scientific } \\
\text { Research and Development (IJTSRD) }\end{array}$ \\
\hline & International Open Access Journal \\
\hline & ISSN No: 2456 - 6470 | www.ijtsrd.com | Volume - 2 | Issue -4 \\
\hline
\end{tabular}

\title{
Study of Machining on High Carbon High Chromium Die Steel Using Wire Cut EDM under Various Conditions
}

\author{
G. Nallaiya ${ }^{1}$, K. S. Sekar ${ }^{2}$ \\ ${ }^{1}$ Department of Tool and Die Making, ${ }^{2}$ Department of Mechanical Engineering \\ ${ }^{1,2}$ Murugappa Polytechnic College, Chennai, India
}

\section{ABSTRACT}

Tool steel are high quality steels made to close compositional and physical tolerances, they are used to make tools for cuttings, forming or shaping material into a part or component adapted to define use. There are various types tool steels are available in this we decided to select D2 material (i.e.) high carbon High chromium die steel. Using wire cut EDM machine we did machining on D2 steel under various condition - ordinary conditions, After Hardening Conditions and after Hardening and tempering Conditions The process parameters viz. Wire diameter, Wire feed rate and Current will be kept constant the wire consumption and machining time measured.

Keywords: Carbon, Chromium Wire, WEDM and Tool

\section{Chapter- I}

\subsection{INTRODUCTION \\ 1.1. Selection of High Carbon High Chromium Die Steel}

There are various type of tool steels are available in which we have selected D2 "high carbon high chromium cold work steel"

All group "D" tool steels except type "D3" are air hardening, and attain full hardness when cooled in still air. Group "D" steels have high resistance to softening at elevated temperatures. These steel also

exits excellent resistances to wear. Especially type D7, which has the highest carbon and vanadium contents. All group D steels particularly the higher carbon types D3,D4 AND D7 - Contain massive carbides that make them susceptible to edge brittleness.

Typically application for group D steels includes long run dies for blanking, forming, threading rolling, and deep drawing, dies for cutting laminations, brick moulds, gages, burnishing tools, rolls, and shear and slitter knives.

\subsection{Heat-Treating the Specimen}

Heat treatment was done on the specimens as per the instructions and details from the heat treater's guide.

The Heat treatment cycle diagram is shown below.

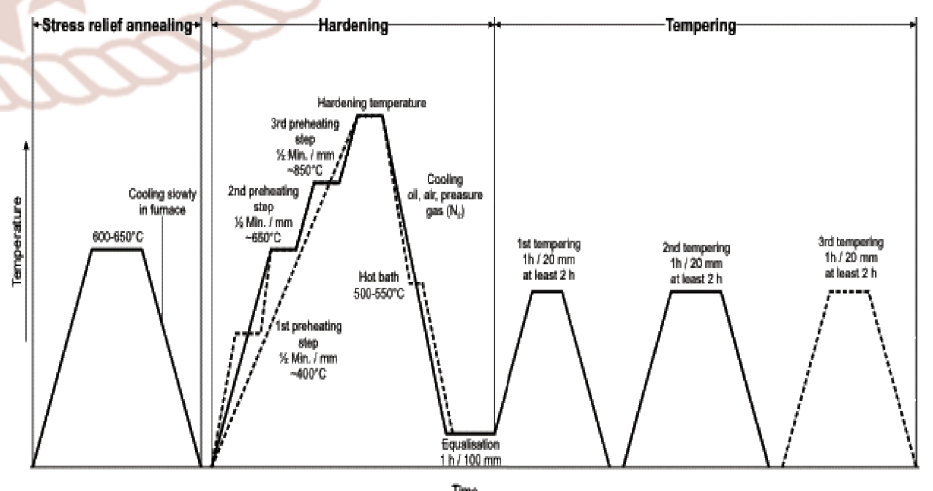

Figure 1: Thermal Cycle Diagram 


\subsection{Selection of Machine}

ELEKTRA MAXICUT CNC Wire cut Machine manufactured by Electronic Machine Tools was used for the Experiment.

\subsection{Part programming}

The geometry of the profile and the motion of the wire electrode tool along the profile is fed to the part programming system using keyboard. The profile geometry is defined in terms of various geometrical definitions of point, line and circle as the wire tool path elements on graphical screen, by using a totally menu driven software. After the profile is fed to the computer, all the numerical information about the path is calculated automatically and its print out is generated,

\subsection{Work Preparation}

For better machining, the work piece material should be, electrically conductive (at least $0.1 /$ micro$\mathrm{ohm} / \mathrm{cm}$ ), Suitable for clamping, on-combustible, onviolent chemical reactions with water, oxygen, hydrogen.

\subsubsection{Wire Electrode}

The wire electrode is required to have a sufficient tensile strength and should be of uniform diameter and free from kink and twist

The Electrode wire material should be Brass/super Alloy, Diameter variation within Plus or minus0.001 $\mathrm{mm}$, Tensile Strength more than $45 \mathrm{Kgf} / \mathrm{mm} 2$ Even winding, free from breaks/kinks.

\subsubsection{Current Carrying Capacity of the Wire}

As a thumb rule, a brass wire of $0.25 \mathrm{~mm}$ in diameter can easily pass $9 \mathrm{~A}$ in water. While machining, wire should always be surrounded by the water column to avoid wire breakage.

\subsubsection{Wire Tension}

A brass wire of $0.25 \mathrm{~mm}$ in diameter can be applied with a maximum tension of 1600 gm. Wire tension determines how much the wire is to be stretched between upper and lower wire guides. More the thickness of the job more the tension is required.

\subsubsection{Wire Feed}

Due to spark erosion, the travelling wire electrode becomes thin and brittle. Wire feed is the rate at which the wire-electrode travels along the wire guide path. It is always desirable to set the wire feed to a higher value. This will result in less wire breakage, better machining stability, and slightly more cutting speed. For example $.25 \mathrm{~mm}$ dia brass wire spool of 5 $\mathrm{Kg}$ will last for 24 hours.

\subsubsection{Overcut}

It is the lateral distance between the wire and work piece during the sparking.

\subsubsection{Wire Compensation (Offset)}

Wire compensation $=(0.5 *$ wire diameter $)+$ over cut.

Wire compensation can be positive or negative depending upon the direction of motion and wire being inside or outside.

\subsubsection{Dielectric strength}

During machining, the conductivity of di electric water changes due to generation of metallic ions and dissolution of ambient gases. The conductivity can be reduced by passing the water through deionizer resin. This is done automatically by the machine.

\subsubsection{Flushing}

Flushing is important to achieve a stable machining condition and plays an important role as far as cutting speed is concerned.

\subsection{Setting Up and Operation}

1.6.1 Job Mounting: Mount the job and clamp it by maximum possible clamps.

1.6.2 Job Reference Point: It is always desirable to have a reference point on the work piece as a start point. The programming should be done with the reference to the starting point. 
International Journal of Trend in Scientific Research and Development (IJTSRD) ISSN: 2456-6470

\subsubsection{Edge Finding}

This function is used to find the edge for setting work co-ordinate system

\subsubsection{Centre Finding}

This function is used to find the centre of the reference hole. Centre finding should be repeated at least twice to verify consistency.

Work piece surface should be free from moisture, rust, dust and grease etc., upper flushing assembly should not be wet, Wire feed should be at $3 \mathrm{mt} / \mathrm{min}$.

\section{Chapter -II}

\section{Experimental Work}

2.1 NC Programming for the Profile to be cut

* NC Program listing of C: NALLU.NCP *

Date of Creation: 7/2/2018

Start Point... X $=0 \mathrm{Y}=0$

LIN $1>>X=4.835, Y=0.000$

$* * * *$ Wire Comp $=0.165$

LIN $2>>X=4.835, Y=4.835$

LIN $3>>X=-4.835, Y=4.835$

LIN $4>>X=-4.835, Y=-4.835$

LIN $\quad 5>>X=4.835, Y=-4.835$

LIN $\quad 6>>X=4.835, Y=0.000$

$* * * *$ Wire Comp $=0$

LIN $\quad 7>>X=0.000, Y=0.000$

$* * * * * * * *$ Machine Stop $* * * * * *$

******** PATH LENGTH ... 48.35

\subsection{Preparation for Machining}

Selection of Wire

$>$ Wire Treading

$>$ Wire Tension and Wire Feed Rate

$>$ Work Piece Mounting

$>$ Wire Positioning Method

$>$ Machining Procedure

\subsection{Parameters to be set for Machining}

After the preparation for machining is over, the flushing and machining parameters were set for programmed profile.

\subsubsection{Machining Parameters}

Machining parameters were set based on the Technology Guidelines provided by the Machine Tool Manufacturer. The following parameters were set during the experiments.

$>$ Pulse ON Time - T ON

$>$ Pulse OFF TIME -T OFF

$>$ Pulse Peak Current(Ip)

$>$ Machining Gap Voltage (Vg)

Servo Sensitivity

Capacitor (C1-C4)

\subsubsection{Fluid Flushing Parameters}

Confirm that conductivity of dielectric fluid is within the specified range. Press the flush switch on the MCP. Adjust dielectric fluid flow valve by watching the flushing pressure fluid flowing from upper and lower flush ports. The flushing pressure should be approx... $12 \mathrm{~kg} / \mathrm{sq} . \mathrm{m}$.

\subsubsection{Servo Parameters}

The following servo adjustments are made:

$>$ AUTO mode Selected

$>$ Machining started by SPARK ON switch.

$>$ Sensitivity knob gradually rotated from position1 in clock wise direction.

$>$ Now the machine tool coordinate table will have a control signals from RACK I. 
International Journal of Trend in Scientific Research and Development (IJTSRD) ISSN: 2456-6470

\subsection{Technology Guidelines and Observation for Work piece}

\subsubsection{Ordinary Conditions}

The following parameters were kept constant during machining and the time taken and wire consumption were noted,

\begin{tabular}{|c|c|c|c|c|c|c|c|c|c|c|c|}
\hline \multirow[t]{2}{*}{ S. no } & \multicolumn{2}{|c|}{ Water } & \multirow[t]{2}{*}{ Ton } & \multirow[t]{2}{*}{ Toff } & \multirow{2}{*}{$\begin{array}{l}\text { I } \\
\text { P }\end{array}$} & \multirow{2}{*}{$\begin{array}{l}\text { CA } \\
\text { P }\end{array}$} & & \multirow[t]{2}{*}{ V } & \multirow[t]{2}{*}{ A } & \multirow[t]{2}{*}{ Time } & \multirow{2}{*}{$\begin{array}{l}\text { Wire } \\
\text { consumption }\end{array}$} \\
\hline & P1 & $\mathrm{P2}$ & & & & & & & & & \\
\hline 1 & \multirow{3}{*}{4} & \multirow{3}{*}{4} & \multirow{3}{*}{3} & \multirow{3}{*}{3} & \multirow{3}{*}{8} & \multirow{3}{*}{3} & \multirow{3}{*}{6} & \multirow{3}{*}{40} & \multirow{3}{*}{7.5} & 36 & 80 \\
\hline 2 & & & & & & & & & & 40 & 84 \\
\hline 3 & & & & & & & & & & 35 & 78 \\
\hline
\end{tabular}

Table 1: Technology Guidelines and Observation for Ordinary Condition Work Piece

\subsubsection{After Hardening}

\begin{tabular}{|c|c|c|c|c|c|c|c|c|c|c|c|}
\hline \multirow[t]{2}{*}{ S. no } & \multicolumn{2}{|c|}{ Water } & \multirow[t]{2}{*}{ Ton } & \multirow[t]{2}{*}{ T off } & \multirow{2}{*}{ P } & \multirow{2}{*}{$\begin{array}{c}\text { CA } \\
\text { P }\end{array}$} & & \multirow[t]{2}{*}{ V } & \multirow[t]{2}{*}{ A } & \multirow[t]{2}{*}{ Time } & \multirow{2}{*}{$\begin{array}{c}\text { Wire } \\
\text { consumption }\end{array}$} \\
\hline & P1 & $\mathrm{P2}$ & & & & & & & & & \\
\hline 1 & \multirow{3}{*}{4} & \multirow{3}{*}{4} & \multirow{3}{*}{3} & & \multirow{3}{*}{8} & \multirow{3}{*}{3} & \multirow{3}{*}{6} & \multirow{3}{*}{40} & \multirow{3}{*}{7.5} & 42 & 80 \\
\hline 2 & & & & & & & & & & 46 & 90 \\
\hline 3 & & & & & & & & & & 44 & 84 \\
\hline
\end{tabular}

Table 2: Technology Guidelines and Observation for Hardened Condition Work Piece

\subsubsection{After Hardening- Tempering}

\begin{tabular}{|c|c|c|c|c|c|c|c|c|c|c|c|}
\hline \multirow[t]{2}{*}{ S.no } & \multicolumn{2}{|c|}{ Water } & \multirow{2}{*}{ Ton } & \multirow[t]{2}{*}{ T off } & \multirow{2}{*}{$\begin{array}{l}\mathrm{I} \\
\mathrm{P}\end{array}$} & \multirow{2}{*}{$\begin{array}{c}\text { CA } \\
\text { P }\end{array}$} & & \multirow[t]{2}{*}{ V } & \multirow[t]{2}{*}{ A } & \multirow[t]{2}{*}{ Time } & \multirow{2}{*}{$\begin{array}{c}\text { Wire } \\
\text { consumption }\end{array}$} \\
\hline & P1 & P2 & & & & & & & & & \\
\hline 1 & \multirow{3}{*}{4} & & \multirow{3}{*}{3} & \multirow{3}{*}{ II 3 er } & \multirow{3}{*}{8} & \multirow{3}{*}{$\ln 3$} & \multirow{3}{*}{6} & \multirow{3}{*}{40} & \multirow{3}{*}{7.5} & 25 & 67 \\
\hline 2 & & & & & & & & & & 29 & 79 \\
\hline 3 & & & & & & & & & & 27 & 72 \\
\hline
\end{tabular}

Table 3: Technology Guidelines and Observation for After Hardened and Tempered Condition Work Piece

\section{Chapter -III}

\section{Results}

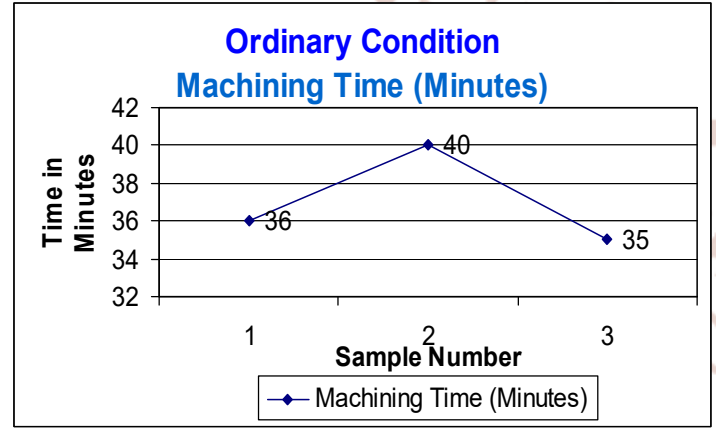

Figure 2: Machining time- Ordinary Condition

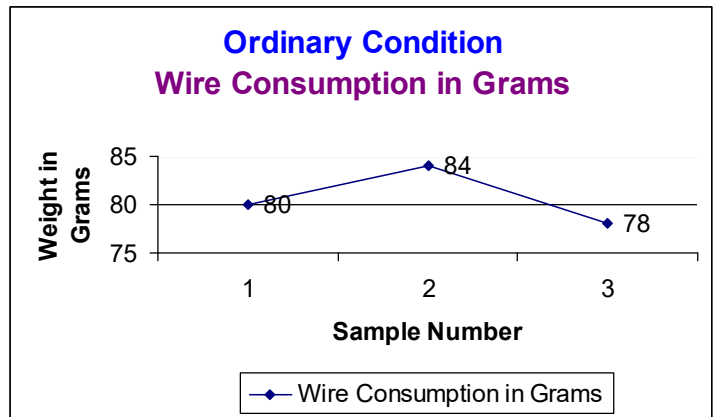

Figure 3: Wire Consumption- Ordinary Condition

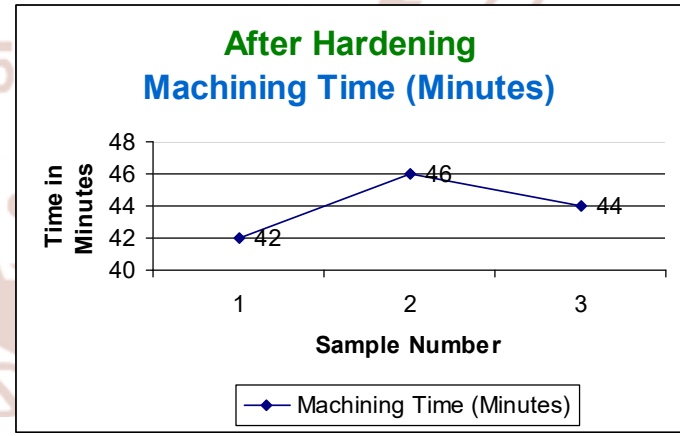

Figure 4: Machining Time- After Hardening

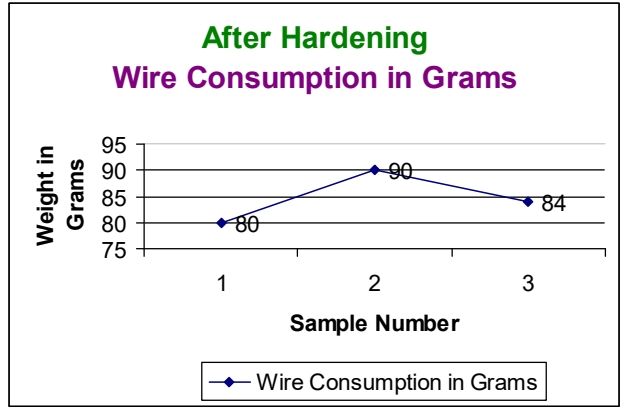

Figure 5: Wire Consumption- After Hardening 
International Journal of Trend in Scientific Research and Development (IJTSRD) ISSN: 2456-6470

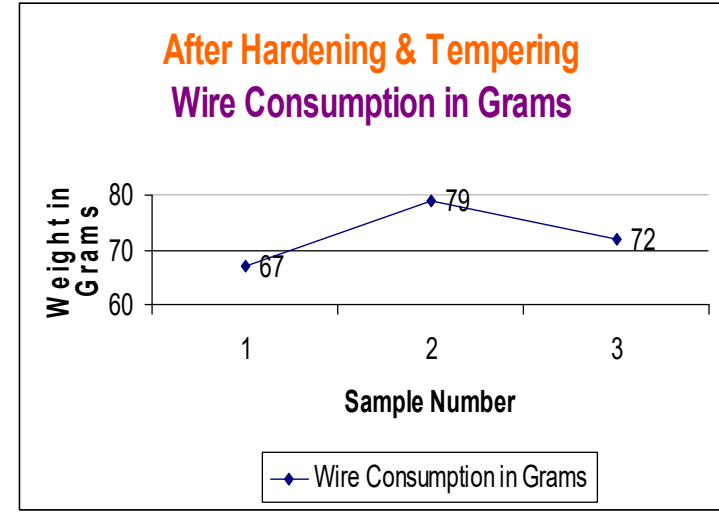

Figure 6: Wire Consumption - After Hardening \& Tempering

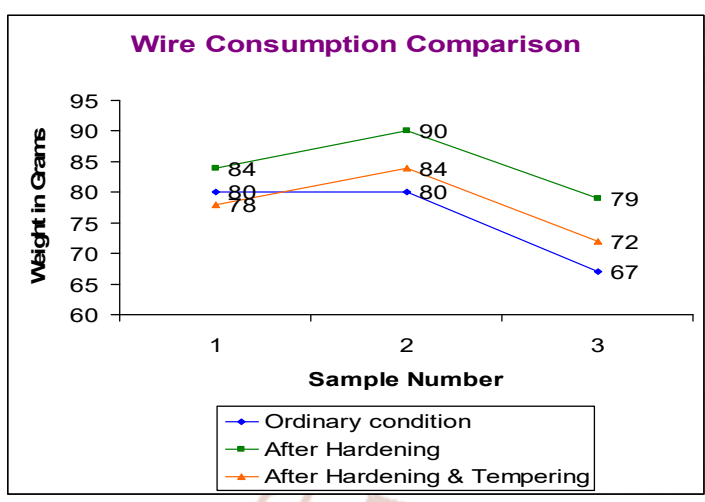

Figure 7: Wire Consumption Comparison

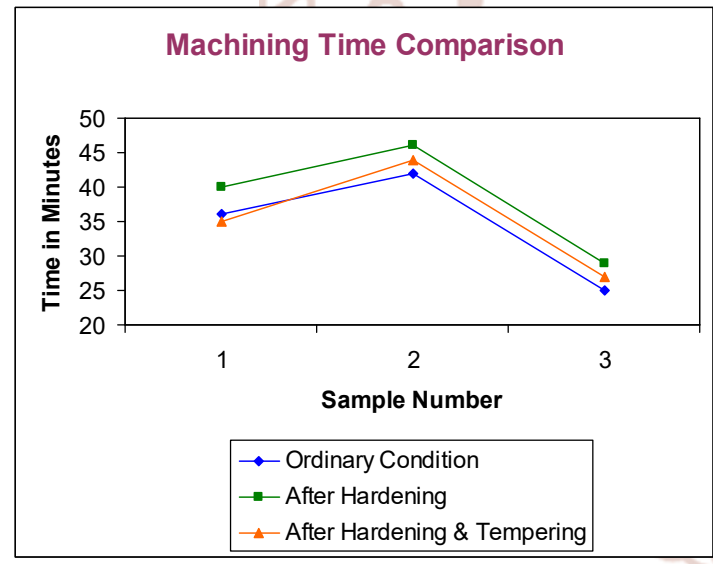

Figure 8: Machining Time Comparison

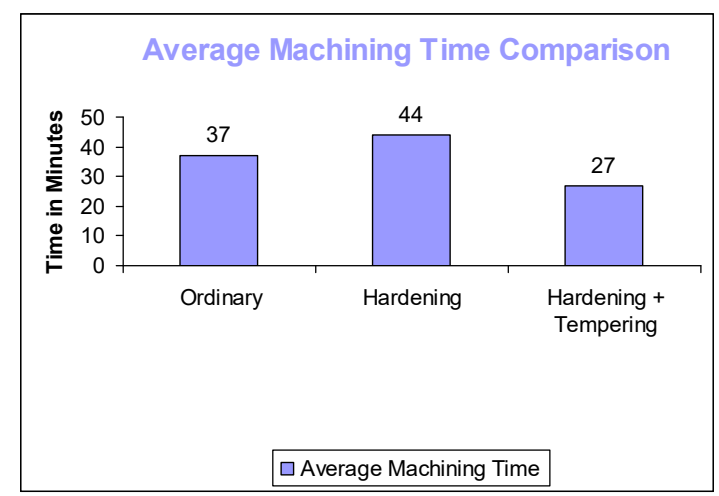

Figure 9: Average Machining Time Comparison

\section{CONCLUSION}

\section{Chapter -IV}

$>$ The Machining time for the hardening and Tempering condition is $27.02 \%$ and $38.64 \%$ lesser than that of ordinary and Hardening condition respectively

$>$ Average wire consumption for the Hardening and Tempering condition is $9.91 \%$ and $14.16 \%$ lesser than that of ordinary and Hardening condition respectively

From the study it is observed that the Hardening and Tempering the specimen has the advantage of average machining time as well as average wire consumption for the machining process

\section{Chapter - V}

\section{References}

1. Rajurkar K. P and Wang W. M "Thermal modeling and on - line Monitoring of Wire EDM" Journal of Material Processing Technology, 38 (1993) pp417-430

2. Kanlayasiri $\mathrm{K}$ and Boonmung $\mathrm{S}$ "Effects of wireEDM machining variable son surface roughness of newly developed DC 53 die steel: Design of experiments and regression model"- Journal of Materials Processing Technology 192-193 (2007) pp 459-464

3. Kanlayasiri $\mathrm{K}$ and Boonmung $\mathrm{S}$ "An investigation on effects of wire-EDM machining parameters on surface roughness of newly developed DC53 diesteel" Journal of Materials Processing Technology 187-188 (2007) pp26-29

4. Aminollah Mohammadi, Alireza Fadaei Tehrani, Ehsan Emanian and Davoud Karimi "Statistical analysis of wire electrical discharge turning on material removal rate" Journal of Materials Processing Technology (2008)pages 7 .pp 171177

5. Haddad, M. J and Fadaei Tehrani A "Material removal rate (MRR) study in the cylindrical wire electrical discharge turning (CWEDT) process" Journal of Materials Processing Technology 199 (2008) pp 369-378

6. Tarng Y. S., Ma S. C and Chung L. K "Determination of optimal cutting parameters in Wire Electrical Discharge Machining" International Journal of Machine Tools and Manufacture Vol.35 , No.12 (1995) pp 1693-1701 
7. Jesudas T., Arunachalam R. M., Jayakumar K. S. and Thiraviam R. "Parametric optimization of wire EDM- A Taguchi approach" Manufacturing Technology Today, Vol.9 August 2007, pp 9-12

8. Rajurkar K. P. and Wang W. M. "WEDM Identification and Adaptive Control for VariableHeight Components" (1994) Annals of the ClRP Vol.43/1/1994 pp 199-204

9. Lok Y. K., and Lee T. C. "Processing of Advanced Ceramics using Wire-cut EDM Process" Journal of Materials Processing Technology 63 (1997) pp839-843

10. Shajan Kuriakose "Characteristics of wire-electro discharge machinedTi6Al4V surface" Journal of Materials Letters 58 (2004) pp 2231-2237

11. Ahmet Hascalyk and Ulas Cayda, "Experimental study of wire electrical discharge machining of AISI D5 tool steel" Journal of Materials Processing Technology 148 (2004) pp 362-367
12. Kadam MS, Basu SK "Optimization of the machining parameters in Wire Electrical Discharge Machining Process using Genetic Algorithm" Manufacturing Technology Today, June 2007 pp 10-15

13. Rao Ch. V. S. P. and Sarcar M. M. M. "Experimental Evaluation of Mathematical correlations for machining Tungsten carbide with CNCWEDM" International Journal of Emerging Technologies and Applications in Engineering, Technology and Sciences in July-Dec (2008) IJETA-ETS(ISSN: 0974-3588) pp 139-145

14. Rao Ch. V. S. P. and Sarcar M .M. M. "Experimental Study and Development of Mathematical Relations for Machining Copper using CNC WEDM" Material Science Research India Vol. 5(2), pp 417-422 ISSN:09733469 Dec -08

(2008)

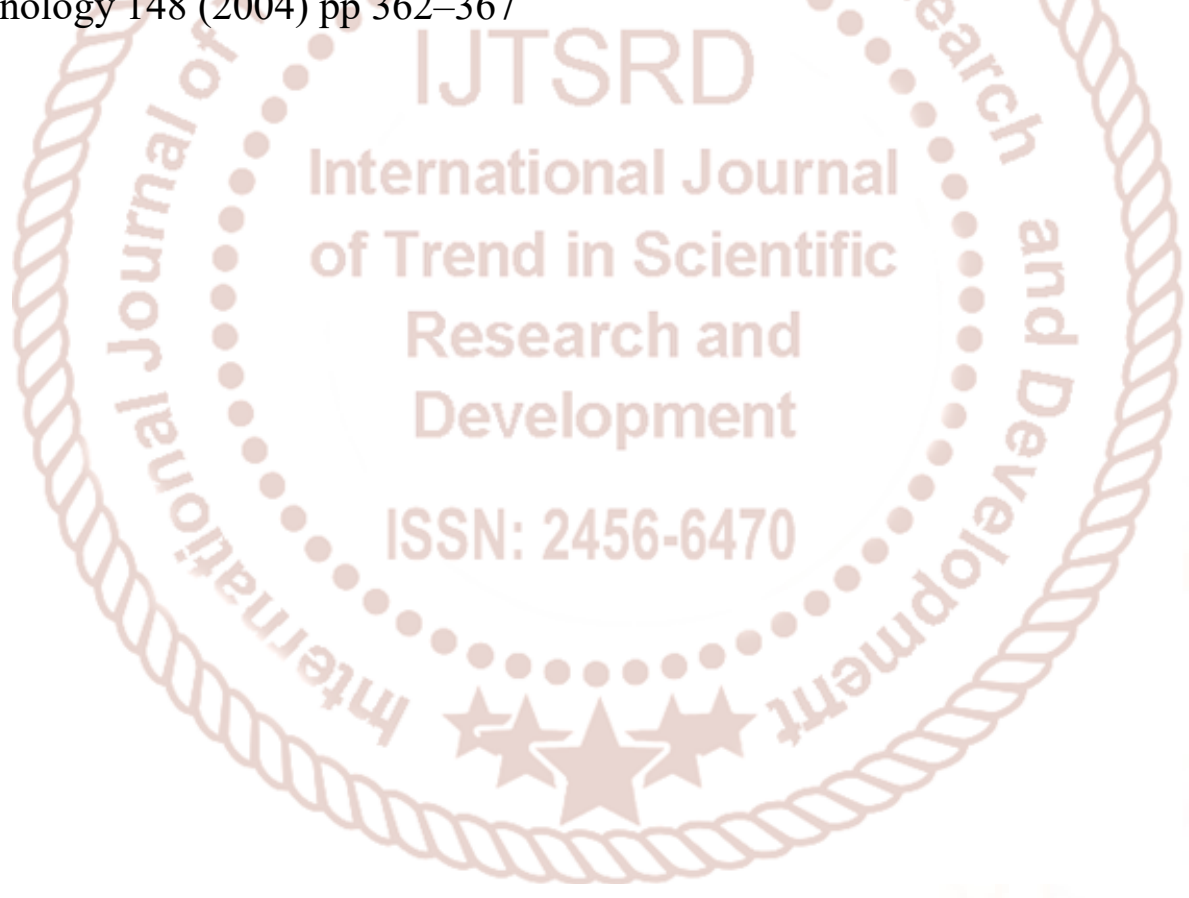

